\title{
Synthesis and Characterization of ZnO Encapsulated Hematite Nanowires and Nanobelts
}

\author{
William C. Lowes and Jingyue (Jimmy) Liu
}

Center for Nanoscience and Department of Physics and Astronomy, University of Missouri-St. Louis, One University Boulevard, St. Louis, Missouri 63121, USA (Email: liuj@umsl.edu)

One dimensional nanocomposite materials have attracted great interest because of their novel physical and chemical properties and their potential applications in nanoscale electronic devices, photovoltaics, sensing, and nanocatalysts. Alpha $\mathrm{Fe}_{2} \mathrm{O}_{3}$ (hematite) nanowires are of interest because of their potential applications in magnetic recording and as a catalyst for the dehydrogenation of ethylbenzene to styrene [1]. Moreover, $\alpha-\mathrm{Fe}_{2} \mathrm{O}_{3}$ composite materials have attracted interest as gas sensors [2]. In this paper we report the synthesis of aligned $\mathrm{ZnO}$ coated $\alpha-\mathrm{Fe}_{2} \mathrm{O}_{3}$ nanowires and nanobelts by two-step synthesis process.

The $\alpha-\mathrm{Fe}_{2} \mathrm{O}_{3}$ nanowires and nanobelts were synthesized by direct thermal oxidation of $\mathrm{Fe}$ substrates [3] in an open air tube furnace for 20 hours at $650^{\circ} \mathrm{C}$. The as synthesized $\alpha-\mathrm{Fe}_{2} \mathrm{O}_{3}$ nanowires and nanobelts were then loaded into a tube furnace with a $\mathrm{ZnO}$ source material located at the center of the tube furnace. The furnace was then heated to $1000^{\circ} \mathrm{C}$ with argon and oxygen flowing through the tube, carrying the evaporated $\mathrm{Zn} / \mathrm{ZnO}$ molecules to lower temperature where they deposited onto the $\alpha-\mathrm{Fe}_{2} \mathrm{O}_{3}$ nanowires and nanobelts. A field emission SEM equipped with an energy dispersive $\mathrm{X}$-ray spectrometer and a Robinson backscattered electron detector was used to characterize the morphology, composition and size distribution of both the uncoated $\alpha-\mathrm{Fe}_{2} \mathrm{O}_{3}$ nanowires and nanobelts and the $\mathrm{ZnO}-\mathrm{Fe}_{2} \mathrm{O}_{3}$ nanocomposites.

Figure 1a shows a SEM image of the $\mathrm{ZnO}$ coated $\alpha-\mathrm{Fe}_{2} \mathrm{O}_{3}$ nanowires. The as synthesized $\alpha-\mathrm{Fe}_{2} \mathrm{O}_{3}$ nanowires were aligned and grew perpendicular to the substrate with an average length and diameter of $10.0 \mu \mathrm{m}$ and $0.3 \mu \mathrm{m}$, respectively. After growth of $\mathrm{ZnO}$, the $\alpha-\mathrm{Fe}_{2} \mathrm{O}_{3}$ nanowires maintained their original growth directions. Figure $1 \mathrm{~b}$ shows a high magnification SEM image of the nanowires, clearly revealing the presence of continuous coating of $\mathrm{ZnO}$ nanoparticles. The diameters and the shapes of the original $\alpha-\mathrm{Fe}_{2} \mathrm{O}_{3}$ nanowires were significantly modified; the average diameter of the $\mathrm{ZnO} / \mathrm{Fe}_{2} \mathrm{O}_{3}$ was about $0.55 \mu \mathrm{m}$. Figure $2 \mathrm{a}$ shows a SEM image of the $\mathrm{ZnO}$ coated $\alpha-\mathrm{Fe}_{2} \mathrm{O}_{3}$ nanobelts. Similar to that of the $\alpha-\mathrm{Fe}_{2} \mathrm{O}_{3}$ nanowires, after growth of $\mathrm{ZnO}$, the orientation and the general morphology of the $\alpha-\mathrm{Fe}_{2} \mathrm{O}_{3}$ nanobelts did not change much. The average length and width of the nanobelts before the $\mathrm{ZnO}$ deposition were measured to be approximately $12.0 \mu \mathrm{m}$ and $1.5 \mu \mathrm{m}$, respectively; the average width of the $\mathrm{ZnO} / \mathrm{Fe}_{2} \mathrm{O}_{3}$ was about $1.8 \mu \mathrm{m}$. Figure $2 \mathrm{~b}$ shows a high magnification SEM image of the nanobelts. It can be clearly seen that during the synthesis process $\mathrm{ZnO}$ encapsulated the $\alpha-\mathrm{Fe}_{2} \mathrm{O}_{3}$ nanobelts. Detailed examination showed that even thin $\mathrm{ZnO}$ nanowires grew out from the $\mathrm{ZnO}-\mathrm{Fe}_{2} \mathrm{O}_{3}$ composite nanobelts. The detailed synthesis-structure relationships and how the morphology of the $\mathrm{ZnO}$ encapsulation varies with the experimental parameters will be discussed [4].

\section{References}

[1] W. Weiss et al., Catal. Lett. 52 (1998) 15. 
[2] J. Shi et al., Mater. Lett. 61 (2007) 5268.

[3] Y. Fu et al., Chem. Phys. Lett. 379 (2003) 373.

[4] This research was supported by the University of Missouri St. Louis.
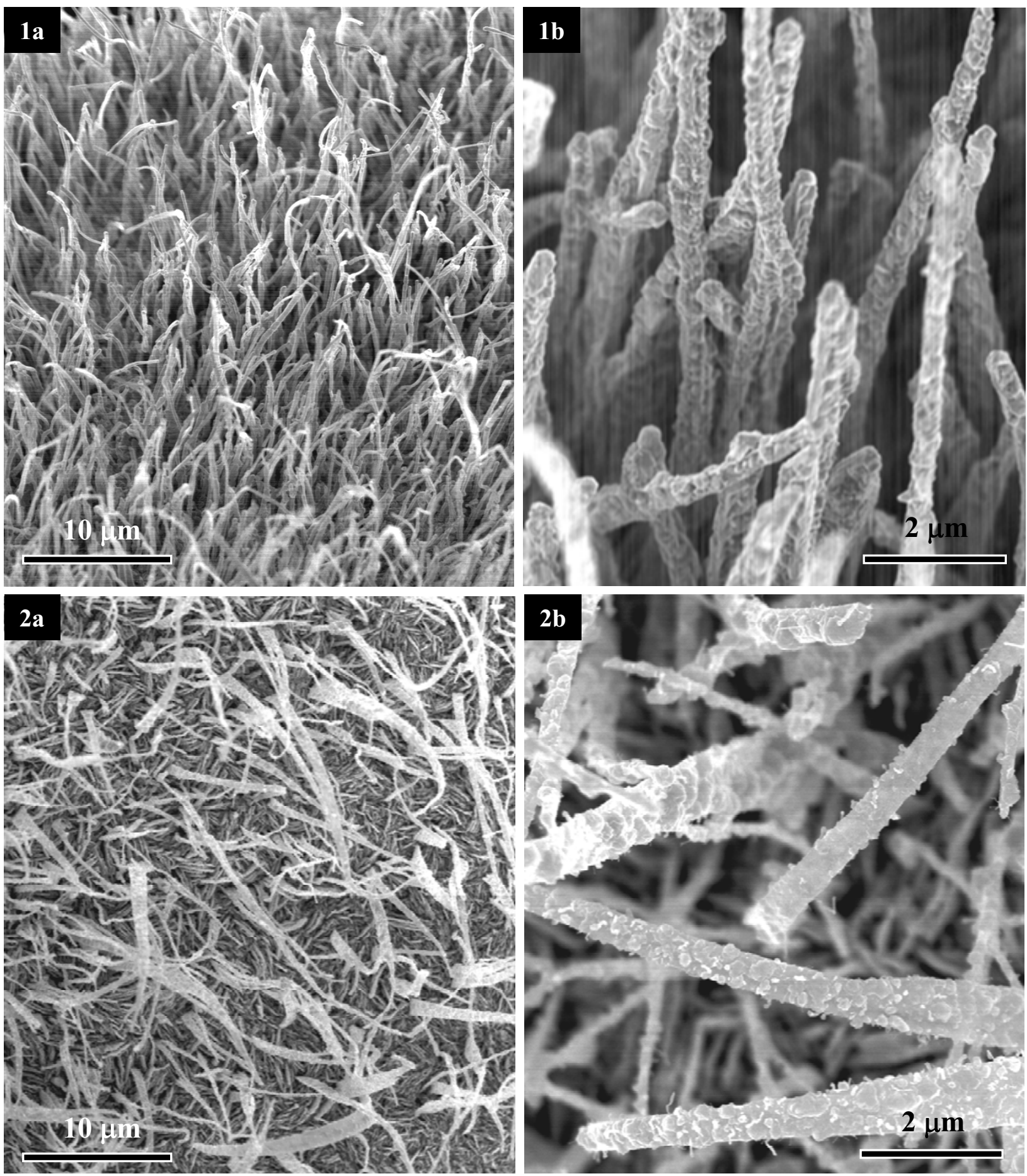

FIG. 1. Low (a) and high (b) magnification SEM images of $\mathrm{ZnO}$ encapsulated $\alpha-\mathrm{Fe}_{2} \mathrm{O}_{3}$ nanowires. FIG. 2. Low (a) and high (b) magnification SEM images of $\mathrm{ZnO}$ encapsulated $\alpha-\mathrm{Fe}_{2} \mathrm{O}_{3}$ nanobelts. 